\title{
The Effects of Light Intensity and Light-curing Time on the Degree of Polymerization of Dental Composite Resins
}

\author{
Chang-Jun BAEK'1, Seok-Hee HYUN², Sang-Kyu LEE', Hyo-Joung SEOL ${ }^{1}$, Hyung-II KIM¹ and Yong Hoon KWON \\ ${ }^{1}$ Department of Dental Materials, College of Dentistry and Medical Research Institute, Pusan National University, Busan 602-739, Korea \\ ${ }^{2}$ Depratment of Chemistry, Purdue University, West Lafayette, IN 47907, USA \\ Corresponding author, Yong Hoon KWON; E-mail: y0k0916@pusan.ac.kr
}

\begin{abstract}
The aim of this study was to investigate the effects of light intensity and light-curing time on the polymerization of composite resins. Four composite resins were light-cured with different light-curing conditions. In the non-thermocycled case, specimens showed almost the same or similar microhardness values if energy density was identical or similar. As the energy density decreased, maximum polymerization shrinkage decreased. At higher energy densities, specimens had a lower coefficient of thermal expansion than at lower energy densities. At the same or similar energy density, most resin products showed coefficient values which were not statistically different. After 10,000 thermocycles, specimens showed decreases of $2.4-16.5 \%$ and $4.6-25.2 \%$ in microhardness and coefficient of thermal expansion respectively. Within the limitations of the present study, it was found that light-curing composite resins with higher energy density was beneficial to acquiring higher microhardness values and lower coefficients of thermal expansion.
\end{abstract}

Key words: Light intensity, Light-curing time, Polymerization

Received Sep 7, 2007: Accepted Jan 25, 2008

\section{INTRODUCTION}

Polymerization of light-curing dental composite resins entails the occurrence of many complicated events. To begin with, composite resins are a mixture of organic and inorganic substances. Consequently, the properties of each constituent substance and the combination thereof inevitably and inextricably affect the results of polymerization. With light-curing composite resins that are polymerized by light, a further understanding of factors related to light is therefore a fundamental endeavor.

To emit photons, various light curing units have been introduced ${ }^{1-6)}$. Light produced by these units has a different spectral profile and light intensity, and thus affects the polymerization process in varied manners. The irradiated light penetrates the specimen and is absorbed by the photoinitiators. In general, the depth of light penetration into a composite resin depends on the type and amount of filler, particle size, and particle size distribution ${ }^{7}$. Besides these factors, specimen thickness also has an important correlation with the number of initiator molecules and attenuation of the incident light.

Camphorquinone (CQ) is one of the most commonly used photoinitiators. However, CQ is yellow and thus its concentration in a composite resin must be kept to a minimum owing to color matching and esthetic concerns. Consequently, full polymerization cannot be achieved. To overcome this limitation, another photoinitiator, 1-phenyl-1,2- propanedione (PPD) - which has absorption peak near $410 \mathrm{~nm}$ - has been proposed as an alternative ${ }^{8)}$.

Through the activation of CQ, formation of free radicals, splitting of $\mathrm{C}=\mathrm{C}$ double bonds to $\mathrm{C}-\mathrm{C}$ single bonds by free radicals, and formation of polymer chains are achieved. In the transformation from monomer structures to polymer chains, the larger van der Waals inter-molecular spacing is replaced by the smaller intra-molecular covalent bond ${ }^{9,10)}$. This process inevitably involves volumetric shrinkage and subsequent contraction stress. In comprehensive studies, commercial composite resins have been found to undergo volumetric shrinkage of $1.7-7.1 \%$, with most composite resins shrinking at $2-3 \%^{11,12}$. Such polymerization shrinkage causes frequent clinical problems such as restoration fractures, increased incidence of recurrent caries, marginal leakage, and postoperative sensitivity ${ }^{13-15)}$.

In the process of polymerization, light intensity and light-curing time are two important factors that impact the number of photons delivered to a specimen. In general, a light intensity of $400 \mathrm{~mW} /$ $\mathrm{cm}^{2}$ for 40 seconds is sufficient to polymerize specimens of $2 \mathrm{~mm}$ thickness ${ }^{16)}$. Recently, light intensity modulation methods for the irradiation mode have been introduced with the expectation that they may reduce polymerization shrinkage. Unlike the conventional method (continuous and constantcuring), these methods employ soft-start protocols such as step curing and ramp curing, or a pulse-delay curing procedure. However, in many cases, the results achieved with these light intensity modulation 
methods were not better than the conventional method. On this score, more studies about polymerization shrinkage are needed in order to arrive at a consistent conclusion ${ }^{17-20)}$.

The purpose of the current study was to evaluate the effects of light intensity and light-curing time on the degree of polymerization of composite resins. For this purpose, microhardness, polymerization shrinkage, thermal expansion, and surface morphology were investigated under repeated thermal stimuli.

\section{MATERIALS AND METHODS}

\section{Specimens and light-curing conditions}

For the present study, four commercially available dental composite resins were used. Their characteristics are listed in Table 1 . Polymerization of specimens was performed using a light curing unit (Elipar Trilight, 3M ESPE, St. Paul, USA). This light curing unit used a quartz-tungsten-halogen (QTH) lamp for light generation and its light tip size was $7 \mathrm{~mm}$. Light was emitted in the range of $400-$ $500 \mathrm{~nm}$. Six different light-curing conditions (light intensity and light-curing time) were chosen for this study: (1) $700 \mathrm{~mW} / \mathrm{cm}^{2}, 40$ seconds; (2) $700 \mathrm{~mW} / \mathrm{cm}^{2}$, 20 seconds; (3) $700 \mathrm{~mW} / \mathrm{cm}^{2}, 10$ seconds; (4) 400 $\mathrm{mW} / \mathrm{cm}^{2}, 70$ seconds; (5) $400 \mathrm{~mW} / \mathrm{cm}^{2}, 30$ seconds; and (6) $400 \mathrm{~mW} / \mathrm{cm}^{2}, 20$ seconds. Light intensity was measured using an internally set radiometer. To achieve the different light intensities, irradiating light was attenuated using optical filters (Thorlabs, Newton, NJ, USA).

\section{Microhardness measurement}

Surface microhardness of the specimens was measured using a Vickers hardness tester (FM-7,
FUTURE-TEC Inc., Japan) in conjunction with the thermocycling process. The thermocycling process was employed to mimic the thermal environment of the oral cavity. Forty-two $((\mathrm{n}=7) \times 6$ curing conditions) specimens from each product were prepared by placing the resin into an acrylic ring mold (7 $\mathrm{mm}$ in diameter and $1 \mathrm{~mm}$ in depth) and covering it with a thin glass slide. The glass slide was pressed firmly to ensure a flat surface. Specimens were polymerized with six different lightcuring conditions. Polymerized specimens were kept in a dark container for 24 hours prior to measurement taking.

After 24 hours, microhardness of the surface before thermocycling was measured using a hardness tester. Two indentations were made on the surface under conditions of a 200-gf load and for a 15-second dwell time. After which, the specimens were immersed in a water bath and repeatedly thermocycled between $4^{\circ} \mathrm{C}$ and $60^{\circ} \mathrm{C}$ with a 30 -second dwell time in each bath. Repeated measurement was performed after 2,000, 5,000, and 10,000 cycles. During the thermocycling process, each additional measurement was performed near the previously measured position to maintain consistency.

\section{Polymerization shrinkage measurement}

To measure polymerization shrinkage $(n=5)$ during the light curing process, a linometer (RB 404, R\&B Inc., Daejon, Korea) was used. This system comprised a specimen holder, a curing light, a shrinkage sensing part, a computer, and a preloaded software.

Specimen resin was located between the glass slide cover and an aluminum disk on the specimen holder. A Teflon (polytetrafluoroethylene, PTFE) mold (1.5 mm thickness with an inner diameter of 4

Table 1 Characteristics of the materials tested in this study

\begin{tabular}{|c|c|c|c|c|c|c|}
\hline \multirow{2}{*}{$\begin{array}{l}\text { Material } \\
\text { Code }\end{array}$} & \multirow{2}{*}{ Composition } & \multirow{2}{*}{ Filler type } & \multicolumn{2}{|c|}{ Filler content } & \multirow{2}{*}{ Batch } & \multirow{2}{*}{ Manufacturer } \\
\hline & & & vol \% & wt \%\# & & \\
\hline $\mathrm{Z} 2$ & Bis-GMA, Bis-EMA, UDMA & Zirconia/silica & $60^{\#}$ & 82 & 20031209 & $\begin{array}{l}\text { 3M ESPE } \\
\text { St. Paul, MN, USA }\end{array}$ \\
\hline FP & Bis-GMA, Bis-EMA, UDMA & Zirconia/silica & $60.3^{*}$ & $75-85$ & 20030306 & $\begin{array}{l}\text { 3M ESPE } \\
\text { St. Paul, MN, USA }\end{array}$ \\
\hline $\mathrm{TPH}$ & $\begin{array}{l}\text { Bis-GMA, Bis-EMA, } \\
\text { TEGDMA }\end{array}$ & Ba-Al-borosilicate glass & $53^{\#}$ & 76 & $\begin{array}{l}040600 \\
0235\end{array}$ & $\begin{array}{l}\text { Dentsply/Detrey } \\
\text { Kostanz, Germany }\end{array}$ \\
\hline $\mathrm{PD}$ & $\begin{array}{l}\text { Bis-GMA,TEGDMA, } \\
\text { Bis-EMA }\end{array}$ & Ba-Al-borosilicate glass & $52.5^{*}$ & 72 & 310697 & $\begin{array}{l}\text { Kerr } \\
\text { Danbury, CT, USA }\end{array}$ \\
\hline
\end{tabular}

Bis-GMA: bisphenol A glycidylmeacrylate; Bis-EMA: Ethoxylated bisphenol A dimethacrylate; TEGDMA: triethylene glycol dimethacrylate; UDMA: urethane dimethacrylate Z2: Z250; PD: Prodigy; FP: Filtek P60; TPH: Spectrum TPH

* : According to the calculation of Braem et al. ${ }^{32}$

\# : According to the manufacturers 
$\mathrm{mm}$ ) was placed over the aluminum disk, and the Teflon mold was filled with the specimen resin. To facilitate the measurement process, the disk was slightly coated with Vaseline. After being completely filled with resin, the Teflon mold was removed. A glass slide was then secured over the resin. The probe of the light curing unit was in contact with the glass slide. Before light curing, the initial position of the aluminum disk was set at zero.

Specimens were prepared under the six different curing conditions. As the resin polymerized, it shrank toward the light source. The aluminum disk under the resin also moved toward the light source. The amount of disk displacement due to polymerization shrinkage was automatically measured using a non-contacting inductive gage for 300 seconds. The shrinkage sensor used in this study was a noncontacting type of which the resolution was $0.1 \mu \mathrm{m}$ with a $100-\mu \mathrm{m}$ measuring range.

\section{Coefficient of thermal expansion measurement}

To evaluate the coefficients of thermal expansion of the products before and after thermocycling, 60 specimens $(1.5 \times 2 \times 12 \mathrm{~mm})$ per product $((\mathrm{n}=5) \times 3$ cycles $\times 4$ curing conditions) were prepared in a metal die. Each specimen was polymerized using the same light curing unit and polymerization condition as previously described. The resin in the metal die was covered with a thin (200 $\mu \mathrm{m}$ thickness), transparent glass slide.

During the photopolymerization process, the end of the light guide was in contact with the cover glass. After removing each specimen from the metal die, the unexposed rear side was light-cured with the same light intensity and light-curing time to ensure complete polymerization. All light-cured specimens were stored in a dark container prior to measurement taking.

From the prepared specimens $(\mathrm{n}=15$ for each condition), the coefficient of thermal expansion was evaluated using a thermomechanical analyzer (TMA) (TMA120, Seiko, Tokyo, Japan). The linear thermal expansion of each specimen was recorded in a temperature range of $30-80^{\circ} \mathrm{C}$ through the probe that was in contact with the specimen. Each specimen was heated at a rate of $5^{\circ} \mathrm{C} / \mathrm{min}$. To reduce additional polymerization shrinkage due to the elevated temperature during measurement, only one measurement per specimen was recorded. After each measurement, the machine was cooled to below $30^{\circ} \mathrm{C}$. Using an internal software of the TMA, coefficient of thermal expansion was calculated within the temperature range of $30-80^{\circ} \mathrm{C}$. The rest of the specimens were repeatedly thermocycled for 5,000 and 10,000 times. After 5,000 thermocycles, five specimens from each curing condition were removed, while the remaining five specimens were removed after 10,000 thermocycles. Coefficients of thermal expansion were then calculated as aforedescribed.

\section{Surface morphology observation}

To observe surface morphology, specimens from each product were prepared by placing the resin into an acrylic ring mold $(7 \mathrm{~mm}$ in diameter and $1 \mathrm{~mm}$ in depth) and then covering them with a thin glass slide. The specimens were light-cured under different light-curing conditions and then kept in a dark container for 24 hours prior to measurement. After 24 hours, the polymerized specimens were polished using SiC paper (\#2000), followed by an alumina paste $(1 \mu \mathrm{m})$ to expose the fillers. Next, the specimens were sonicated in distilled water.

Prepared specimens were immersed in a water bath and repeatedly thermocycled with the same conditions as described above. After 10,000 thermocycles, specimens were removed from the water bath, rinsed with running water, dried, and gold-coated. Surface morphology observation was performed using a scanning electron microscope (SEM) (S-4200, Hitachi Co., Tokyo, Japan).

\section{Statistical analysis}

Polymerization shrinkage and coefficient of thermal expansion results were analyzed using a two-way ANOVA test. Tukey's test then followed the multiple comparison test if necessary. All results were analyzed at a significance level of $5 \%$.

\section{RESULTS}

\section{Microhardness}

Table 2 shows the microhardness values of specimens for different light intensities and light-curing times with different numbers of thermocycles. In the control (non-thermocycled) case, if the energy density (=light intensity $\left(\mathrm{mW} / \mathrm{cm}^{2}\right) \cdot$ light-curing time $(\mathrm{s})$ ) was identical or similar, Z2 and FP showed almost the same microhardness values within the same product. TPH and PD, on the other hand, showed slightly different microhardness values within the same product, although the difference was very small. The ratios of energy densities between 1 and 3 or 4 and 6 were 4 and 3.5 respectively. However, the ratios of microhardness values between 1 and 3 or 4 and 6 for each product were close to 1 . On the overall, differences in microhardness values between 1 and 3 or 4 and 6 for all the products ranged from 5.5 to $13.1 \%$.

After 10,000 thermocycles, and compared to the control case, specimens of Z2, FP, and TPH showed a decrease of $11.1-16.5 \%$ in microhardness depending on product and energy density, whereas PD showed a decrease of only $2.4-8.7 \%$ in microhardness. 
According to statistical analysis, within the same product and in terms of thermocycling, there were significant differences in microhardness among the same or similar energy densities $(p<0.05)$. However, the results were not consistent and the differences in microhardness values were minor whether the specimens were thermocycled or not.

\section{Polymerization shrinkage}

Figure 1 shows the polymerization shrinkage of specimens during a 300-second period at different energy densities but with the same specimen thickness. As clearly seen from the increment slope, shrinkage rapidly increased during the first 40second period - which was the length of light curing time, and then it reached a plateau (Fig. 1a). In case of 10-second light curing, rapid shrinkage was maintained for only 10 seconds, and then it reached a plateau (Fig. 1b). In case of 20 -second light curing, rapid shrinkage continued a little longer than 20 seconds (Fig. 1d). On the other hand, in the case of 70 -second light curing, the shrinkage process did not continue for 70 seconds. Rapid increase of shrinkage stopped nearly after 40 seconds and then reached a plateau (Fig. 1c).

Table 3 shows the maximum polymerization shrinkage $(\mu \mathrm{m})$ of specimens in $1.5-\mathrm{mm}$-thick specimens during light curing. As energy density decreased, maximum shrinkage also decreased regardless of product. For the same light intensity, a longer light-curing time yielded a greater shrinkage than a shorter light-curing time. Z2 and FP did not

Table 2 Microhardness (Hv) values of top surface under various light-curing and thermocycling conditions

\begin{tabular}{|c|c|c|c|c|c|c|}
\hline \multirow{2}{*}{ Code } & \multirow{2}{*}{ Light curing } & \multicolumn{4}{|c|}{ Thermocycling (cycles) } & \multirow[b]{2}{*}{$p$-value } \\
\hline & & $0^{1}$ & $2000^{2}$ & $5000^{3}$ & $10000^{4}$ & \\
\hline \multirow{7}{*}{$\mathrm{Z} 2$} & $1^{\mathrm{A}}$ & $77.3 \pm 1.5$ & $71.8 \pm 1.0$ & $69.3 \pm 1.2$ & $65.5 \pm 0.9$ & \multirow{6}{*}{$\begin{array}{l}a<0.001 \\
b<0.001\end{array}$} \\
\hline & $2^{\mathrm{B}}$ & $76.7 \pm 1.4$ & $66.6 \pm 0.6$ & $65.7 \pm 0.8$ & $64.7 \pm 0.9$ & \\
\hline & $3^{\mathrm{C}}$ & $72.2 \pm 1.4$ & $65.8 \pm 1.4$ & $64.6 \pm 0.7$ & $63.9 \pm 0.5$ & \\
\hline & $4^{\mathrm{D}}$ & $77.5 \pm 1.5$ & $68.9 \pm 1.1$ & $66.2 \pm 0.8$ & $64.7 \pm 0.7$ & \\
\hline & $5^{\mathrm{B}}$ & $76.4 \pm 0.7$ & $67.9 \pm 0.9$ & $65.1 \pm 0.9$ & $64.3 \pm 0.6$ & \\
\hline & $6^{\mathrm{E}}$ & $72.0 \pm 1.0$ & $65.6 \pm 0.9$ & $64.2 \pm 0.7$ & $64.0 \pm 0.6$ & \\
\hline & & $0^{1}$ & $2000^{2}$ & $5000^{3}$ & $10000^{4}$ & \\
\hline \multirow{7}{*}{ FP } & $1^{\mathrm{A}}$ & $81.4 \pm 1.6$ & $69.7 \pm 1.5$ & $69.2 \pm 1.7$ & $69.2 \pm 0.8$ & \multirow{6}{*}{$\begin{array}{l}a<0.001 \\
b<0.001\end{array}$} \\
\hline & $2^{\mathrm{B}}$ & $78.1 \pm 1.0$ & $68.3 \pm 0.9$ & $66.5 \pm 0.8$ & $66.5 \pm 1.0$ & \\
\hline & $3^{\mathrm{C}}$ & $74.6 \pm 1.2$ & $67.7 \pm 0.7$ & $65.4 \pm 0.5$ & $63.6 \pm 1.0$ & \\
\hline & $4^{\mathrm{A}}$ & $81.1 \pm 2.3$ & $71.5 \pm 0.6$ & $70.6 \pm 1.1$ & $69.6 \pm 0.8$ & \\
\hline & $5^{\mathrm{B}}$ & $78.4 \pm 1.6$ & $69.4 \pm 1.2$ & $68.2 \pm 1.1$ & $66.0 \pm 0.8$ & \\
\hline & $6^{\mathrm{C}}$ & $74.8 \pm 1.4$ & $67.3 \pm 0.6$ & $64.9 \pm 0.6$ & $64.6 \pm 0.8$ & \\
\hline & & $0^{1}$ & $2000^{2}$ & $5000^{3}$ & $10000^{4}$ & \\
\hline \multirow{7}{*}{$\mathrm{TPH}$} & $1^{\mathrm{A}}$ & $57.1 \pm 1.5$ & $51.0 \pm 0.9$ & $49.0 \pm 0.7$ & $48.9 \pm 1.3$ & \multirow{6}{*}{$\begin{array}{l}a<0.001 \\
b<0.001\end{array}$} \\
\hline & $2^{\mathrm{B}}$ & $55.7 \pm 0.9$ & $48.6 \pm 0.8$ & $46.1 \pm 0.9$ & $47.5 \pm 0.6$ & \\
\hline & $3^{\mathrm{C}}$ & $53.0 \pm 0.9$ & $45.7 \pm 0.9$ & $43.6 \pm 0.6$ & $45.5 \pm 0.4$ & \\
\hline & $4^{\mathrm{B}}$ & $54.5 \pm 1.0$ & $48.1 \pm 0.8$ & $46.7 \pm 0.7$ & $45.9 \pm 1.2$ & \\
\hline & $5^{\mathrm{D}}$ & $53.2 \pm 0.7$ & $46.8 \pm 0.8$ & $46.0 \pm 0.3$ & $45.7 \pm 0.8$ & \\
\hline & $6^{\mathrm{E}}$ & $51.5 \pm 1.1$ & $44.0 \pm 0.8$ & $43.2 \pm 0.3$ & $44.7 \pm 0.8$ & \\
\hline & & $0^{1}$ & $2000^{2}$ & $5000^{2}$ & $10000^{3}$ & \\
\hline \multirow{6}{*}{$\mathrm{PD}$} & $1^{\mathrm{A}}$ & $50.5 \pm 0.9$ & $50.2 \pm 1.2$ & $51.9 \pm 1.6$ & $49.3 \pm 1.2$ & \multirow{6}{*}{$\begin{array}{l}a<0.001 \\
b<0.001\end{array}$} \\
\hline & $2^{\mathrm{B}}$ & $50.4 \pm 0.5$ & $47.0 \pm 0.8$ & $42.7 \pm 1.4$ & $46.0 \pm 0.7$ & \\
\hline & $3^{\mathrm{C}}$ & $46.1 \pm 0.8$ & $45.7 \pm 1.0$ & $46.1 \pm 0.5$ & $44.7 \pm 0.8$ & \\
\hline & $4^{\mathrm{D}}$ & $51.2 \pm 0.9$ & $49.2 \pm 0.6$ & $48.4 \pm 1.0$ & $47.9 \pm 0.5$ & \\
\hline & $5^{\mathrm{B}}$ & $49.7 \pm 0.6$ & $47.5 \pm 0.8$ & $48.1 \pm 0.8$ & $46.4 \pm 0.5$ & \\
\hline & $6^{\mathrm{E}}$ & $44.5 \pm 0.8$ & $43.8 \pm 1.2$ & $43.9 \pm 0.6$ & $43.1 \pm 1.1$ & \\
\hline
\end{tabular}

1: $700 \mathrm{~mW} / \mathrm{cm}^{2}$ and $40 \mathrm{~s} ; 2: 700 \mathrm{~mW} / \mathrm{cm}^{2}$ and $20 \mathrm{~s} ; 3: 700 \mathrm{~mW} / \mathrm{cm}^{2}$ and $10 \mathrm{~s} ; 4: 400 \mathrm{~mW} / \mathrm{cm}^{2}$ and $70 \mathrm{~s} ; 5: 400 \mathrm{~mW} / \mathrm{cm}^{2}$, and $30 \mathrm{~s} ; 6: 400 \mathrm{~mW} / \mathrm{cm}^{2}$ and $20 \mathrm{~s}$.

* Statistically significant difference on energy density is shown by superscript letters ${ }^{\mathrm{A}}$, B, C, and by superscript numbers ${ }^{1,2,3}$ for the number of thermocycles. Same letters or numbers indicate differences that are not statistically significant $(\mathrm{p}<0.05)$.

* On $p$-values, the letters 'a' and 'b' denote energy density and number of thermocycles respectively. 
show statistically different polymerization shrinkage. Light-curing conditions 1 and 4 yielded statistically different polymerization shrinkage values.

\section{Coefficient of thermal expansion}

Table 4 shows the coefficients of thermal expansion of specimens before and after the thermocycling process under different light-curing conditions. At higher energy densities, specimens had lower coefficients of thermal expansion than at lower energy densities. As thermocyling proceeded, the coefficient of thermal expansion gradually decreased regardless of product and light-curing condition. The coefficients of non-thermocycled specimens (control) ranged from 39.9 to $59.1 \times 10^{-6} /{ }^{\circ} \mathrm{C}$. After 10,000 thermocycles, the coefficients decreased by $4.6-$
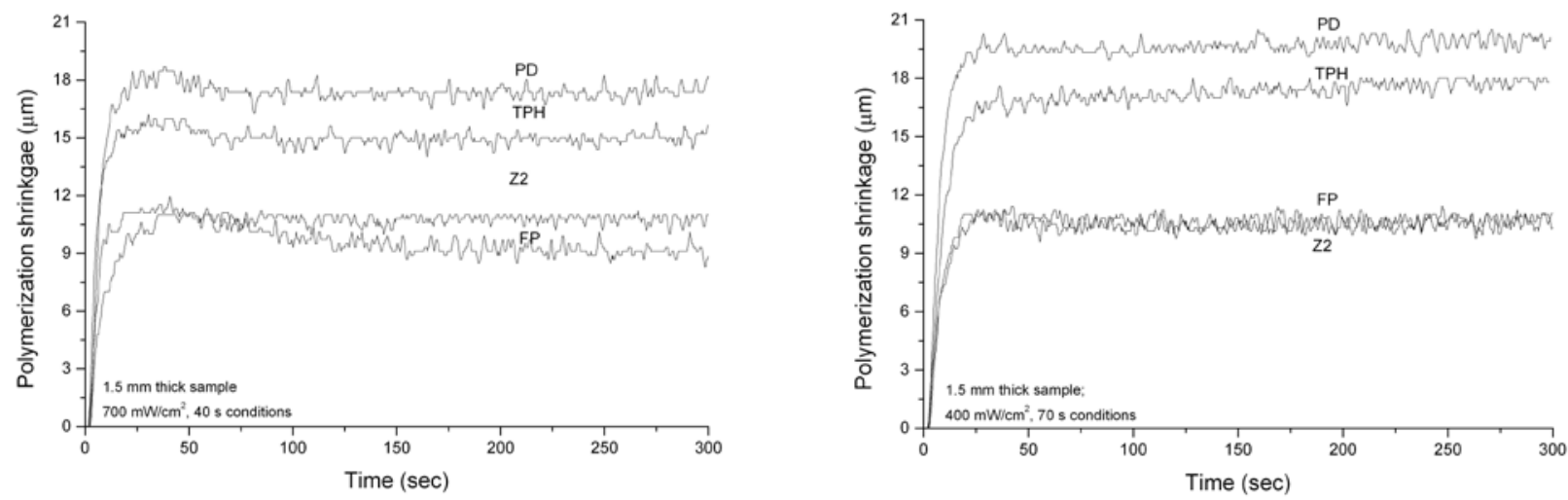

(a)
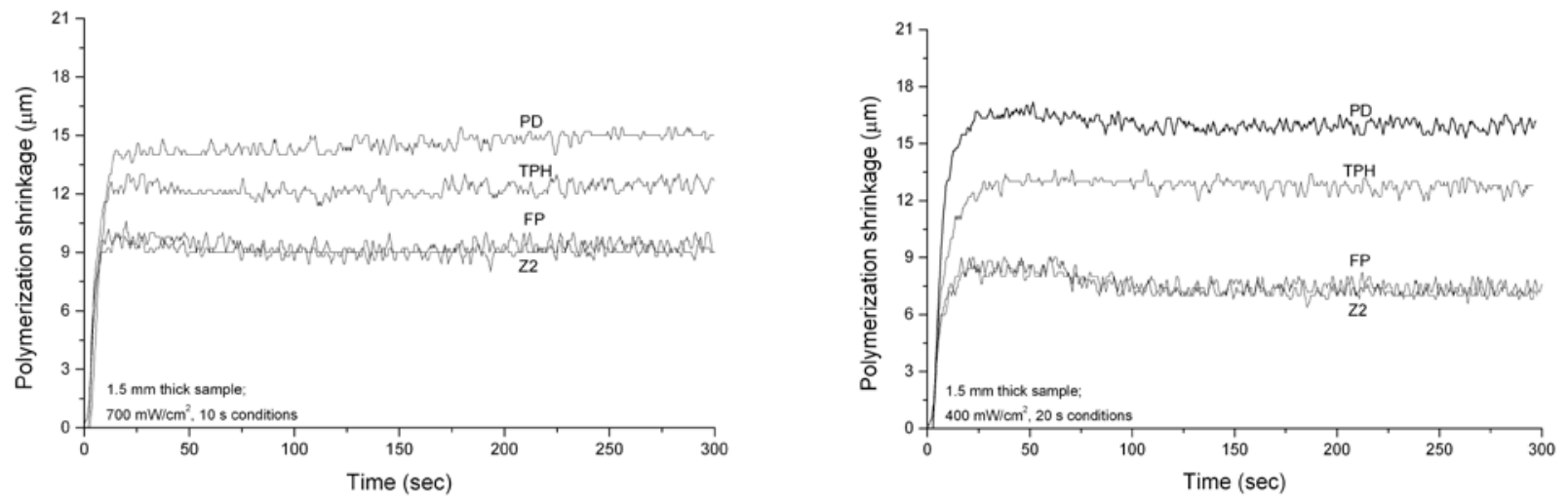

(b)

(d)

Fig. 1 Polymerization shrinkage in 1.5-mm-thick specimen under these conditions: (a) $700 \mathrm{~mW} / \mathrm{cm}^{2}$ light intensity and $40 \mathrm{~s}$ exposure; $700 \mathrm{~mW} / \mathrm{cm}^{2}$ light intensity and $10 \mathrm{~s}$ exposure; $400 \mathrm{~mW} / \mathrm{cm}^{2}$ light intensity and $70 \mathrm{~s}$ exposure; and $400 \mathrm{~mW} / \mathrm{cm}^{2}$ light intensity and $20 \mathrm{~s}$ exposure.

Table 3 Maximum polymerization shrinkage $(\mu \mathrm{m})$ in 1.5-mm-thick specimen under various light-curing conditions

\begin{tabular}{|c|c|c|c|c|c|c|c|}
\hline \multirow{2}{*}{ Code } & \multicolumn{6}{|c|}{ Light-curing condition } & \multirow[b]{2}{*}{$p$-values } \\
\hline & $1^{12}$ & $2^{23}$ & $3^{34}$ & $4^{5}$ & $5^{123}$ & $6^{4}$ & \\
\hline $\mathrm{Z} 2^{\mathrm{A}}$ & $11.2 \pm 0.5$ & $9.3 \pm 0.5$ & $9.0 \pm 1.0$ & $11.6 \pm 1.1$ & $9.6 \pm 0.5$ & $7.6 \pm 0.5$ & \multirow{4}{*}{$\begin{array}{l}a<0.001 \\
b<0.001\end{array}$} \\
\hline $\mathrm{FP}^{\mathrm{A}}$ & $9.6 \pm 1.3$ & $9.5 \pm 1.5$ & $9.3 \pm 0.6$ & $11.0 \pm 1.0$ & $9.6 \pm 1.1$ & $7.0 \pm 1.0$ & \\
\hline $\mathrm{TPH}^{\mathrm{B}}$ & $15.2 \pm 1.0$ & $14.0 \pm 1.0$ & $13.0 \pm 1.0$ & $18.0 \pm 1.0$ & $13.3 \pm 1.1$ & $13.0 \pm 1.0$ & \\
\hline $\mathrm{PD}^{\mathrm{C}}$ & $19.0 \pm 0.6$ & $17.5 \pm 1.0$ & $15.3 \pm 0.6$ & $20.1 \pm 3.1$ & $18.3 \pm 0.5$ & $16.6 \pm 0.5$ & \\
\hline
\end{tabular}

1: $700 \mathrm{~mW} / \mathrm{cm}^{2}$ and $40 \mathrm{~s} ; 2: 700 \mathrm{~mW} / \mathrm{cm}^{2}$ and $20 \mathrm{~s} ; 3: 700 \mathrm{~mW} / \mathrm{cm}^{2}$ and $10 \mathrm{~s} ; 4: 400 \mathrm{~mW} / \mathrm{cm}^{2}$ and $70 \mathrm{~s} ; 5: 400 \mathrm{~mW} / \mathrm{cm}^{2}$ and $30 \mathrm{~s} ; 6: 400 \mathrm{~mW} / \mathrm{cm}^{2}$ and $20 \mathrm{~s}$.

* Statistically significant difference on resin products is shown by superscript letters A, B, C, and by superscript numbers 1,2, 3 for energy density. Same letters or numbers indicate differences that are not statistically significant $(\mathrm{p}<0.05)$.

* On $p$-values, the letters 'a' and 'b' denote resin product and energy density respectively. 
Table 4 Coefficients of thermal expansion $\left(\times 10^{-6} /{ }^{\circ} \mathrm{C}\right)$ under various curing and thermocycling conditions

\begin{tabular}{|c|c|c|c|c|c|}
\hline \multirow{2}{*}{ Code } & \multirow{2}{*}{ Light curing } & \multicolumn{3}{|c|}{ Thermocycling (cycles) } & \multirow[b]{2}{*}{$p$-values } \\
\hline & & $0^{1}$ & $5000^{2}$ & $10000^{2}$ & \\
\hline \multirow{4}{*}{$\mathrm{Z} 2$} & $1^{\mathrm{BC}}$ & $43.6 \pm 1.3$ & $38.3 \pm 2.1$ & $35.0 \pm 1.9$ & \multirow{4}{*}{$\begin{array}{l}a<0.003 \\
b<0.001\end{array}$} \\
\hline & $3^{\mathrm{A}}$ & $47.7 \pm 3.1$ & $42.8 \pm 3.5$ & $40.7 \pm 1.9$ & \\
\hline & $4^{\mathrm{C}}$ & $44.2 \pm 1.4$ & $39.9 \pm 2.5$ & $38.4 \pm 1.3$ & \\
\hline & $6^{\mathrm{AB}}$ & $50.8 \pm 1.6$ & $44.9 \pm 2.7$ & $44.2 \pm 3.3$ & \\
\hline & & $0^{1}$ & $5000^{2}$ & $10000^{2}$ & \\
\hline \multirow{4}{*}{ FP } & $1^{\mathrm{A}}$ & $45.5 \pm 0.6$ & $39.7 \pm 0.8$ & $35.6 \pm 1.8$ & \multirow{4}{*}{$\begin{array}{l}a<0.001 \\
b<0.001\end{array}$} \\
\hline & $3^{\mathrm{B}}$ & $45.6 \pm 1.1$ & $37.5 \pm 0.8$ & $35.8 \pm 0.4$ & \\
\hline & $4^{\mathrm{AB}}$ & $39.9 \pm 0.8$ & $36.0 \pm 0.3$ & $35.3 \pm 1.5$ & \\
\hline & $6^{\mathrm{C}}$ & $41.3 \pm 4.0$ & $37.7 \pm 1.1$ & $34.9 \pm 0.6$ & \\
\hline & & $0^{1}$ & $5000^{2}$ & $10000^{3}$ & \\
\hline \multirow{4}{*}{ TPH } & $1^{\mathrm{A}}$ & $50.0 \pm 2.0$ & $42.6 \pm 1.9$ & $39.6 \pm 2.1$ & \multirow{4}{*}{$\begin{array}{l}a<0.001 \\
b<0.001\end{array}$} \\
\hline & $3^{\mathrm{AB}}$ & $59.1 \pm 4.3$ & $47.1 \pm 0.9$ & $44.2 \pm 2.5$ & \\
\hline & $4^{\mathrm{C}}$ & $47.9 \pm 1.5$ & $46.4 \pm 1.1$ & $45.7 \pm 1.0$ & \\
\hline & $6^{\mathrm{BC}}$ & $51.3 \pm 4.0$ & $48.7 \pm 2.1$ & $48.1 \pm 2.7$ & \\
\hline & & $0^{1}$ & $5000^{2}$ & $10000^{2}$ & \\
\hline \multirow{4}{*}{ PD } & $1^{\mathrm{A}}$ & $51.2 \pm 0.8$ & $50.1 \pm 3.4$ & $46.7 \pm 0.7$ & \multirow{4}{*}{$\begin{array}{l}a<0.001 \\
b<0.001\end{array}$} \\
\hline & $3^{\mathrm{B}}$ & $56.1 \pm 2.7$ & $52.5 \pm 2.6$ & $51.2 \pm 1.9$ & \\
\hline & $4^{\mathrm{AC}}$ & $51.2 \pm 3.5$ & $46.9 \pm 6.8$ & $45.6 \pm 2.5$ & \\
\hline & $6^{\mathrm{BC}}$ & $56.8 \pm 3.9$ & $48.2 \pm 2.8$ & $46.3 \pm 3.0$ & \\
\hline
\end{tabular}

1: $700 \mathrm{~mW} / \mathrm{cm}^{2}$ and $40 \mathrm{~s} ; 3: 700 \mathrm{~mW} / \mathrm{cm}^{2}$ and $10 \mathrm{~s} ; 4: 400 \mathrm{~mW} / \mathrm{cm}^{2}$ and $70 \mathrm{~s} ; 6: 400 \mathrm{~mW} / \mathrm{cm}^{2}$ and $20 \mathrm{~s}$.

* Statistically significant difference on energy density is shown by superscript letters ${ }^{\mathrm{A}, \mathrm{B}, \mathrm{C}}$, and by superscript numbers ${ }^{1,2,3}$ on number of thermocycles. Same letters or numbers indicate differences that are not statistically significant $(p<0.05)$.

* On $p$-values, the letters 'a' and 'b' denote energy density and number of thermocycles respectively.

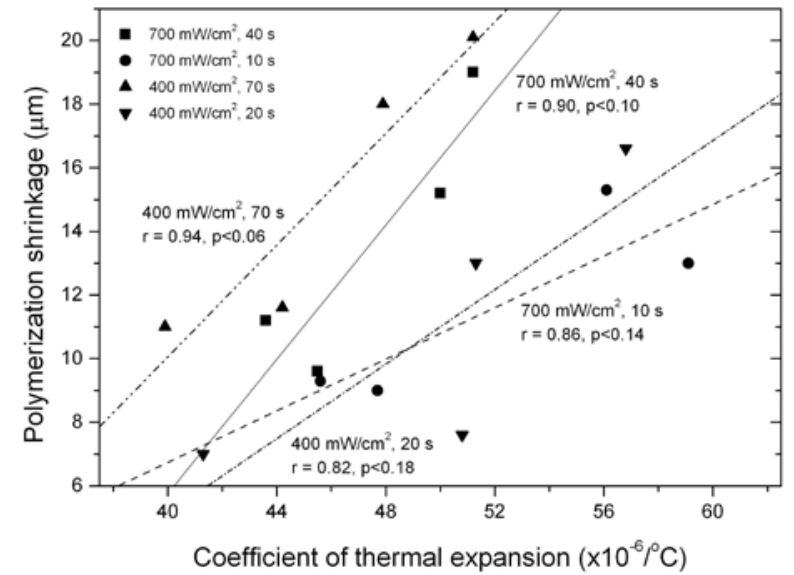

Fig. 2 Relationship between polymerization shrinkage and coefficient of thermal expansion for different light-curing conditions. (As the curve increased in each correlation curve, the filler content of the specimens decreased.)
25.2\% depending on the curing condition and product. Non-thermocycled specimens yielded statistically different thermal expansion coefficient values compared to the thermocycled specimens regardless of product. At the same or similar energy density, most resin products showed statistically similar coefficient values except for cases 3 and 6 in FP and 1 and 4 in TPH.

Figure 2 shows the relationship between the coefficient of thermal expansion and polymerization shrinkage of the specimens. Specimens of lower coefficient of thermal expansion exhibited less polymerization shrinkage due to their higher filler content. The linear correlation coefficient ranged from 0.82 to 0.94 .

\section{Surface morphology}

Surface morphology images of the specimens before and after the thermocycling process under two different light-curing conditions are shown in Fig. 3. Each product exhibited different filler sizes and shapes. Fillers in Z2 and FP were round, whereas fillers in PD and TPH had an irregular shape with sharp edges. After 10,000 thermocycles, fillers in Z2 and FP remained intact. However, some fillers in PD and TPH, exhibited detachment from the resin 

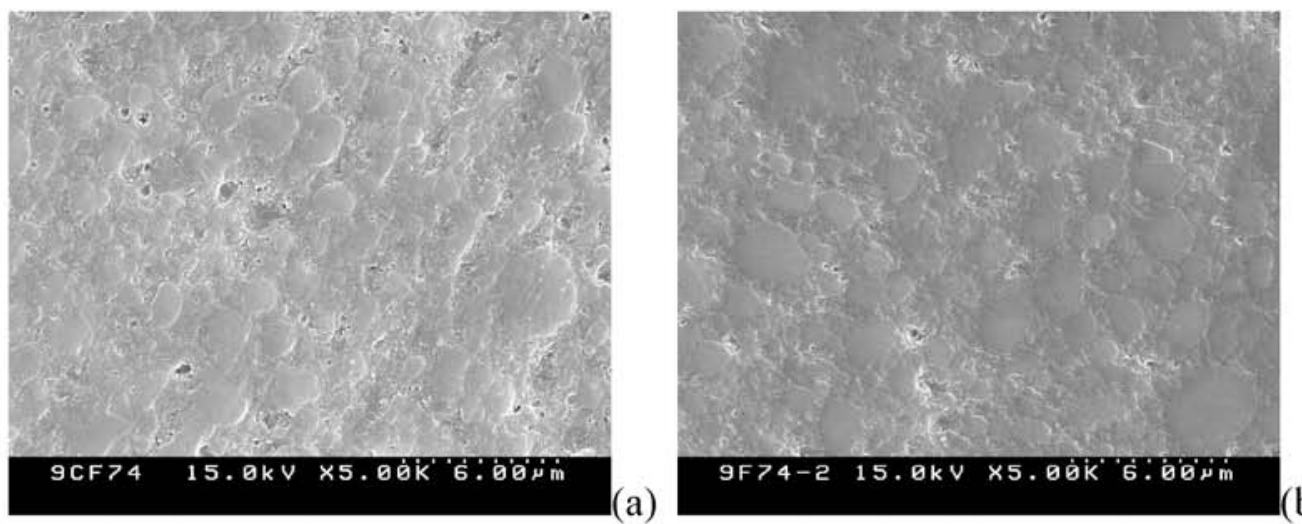

(b)
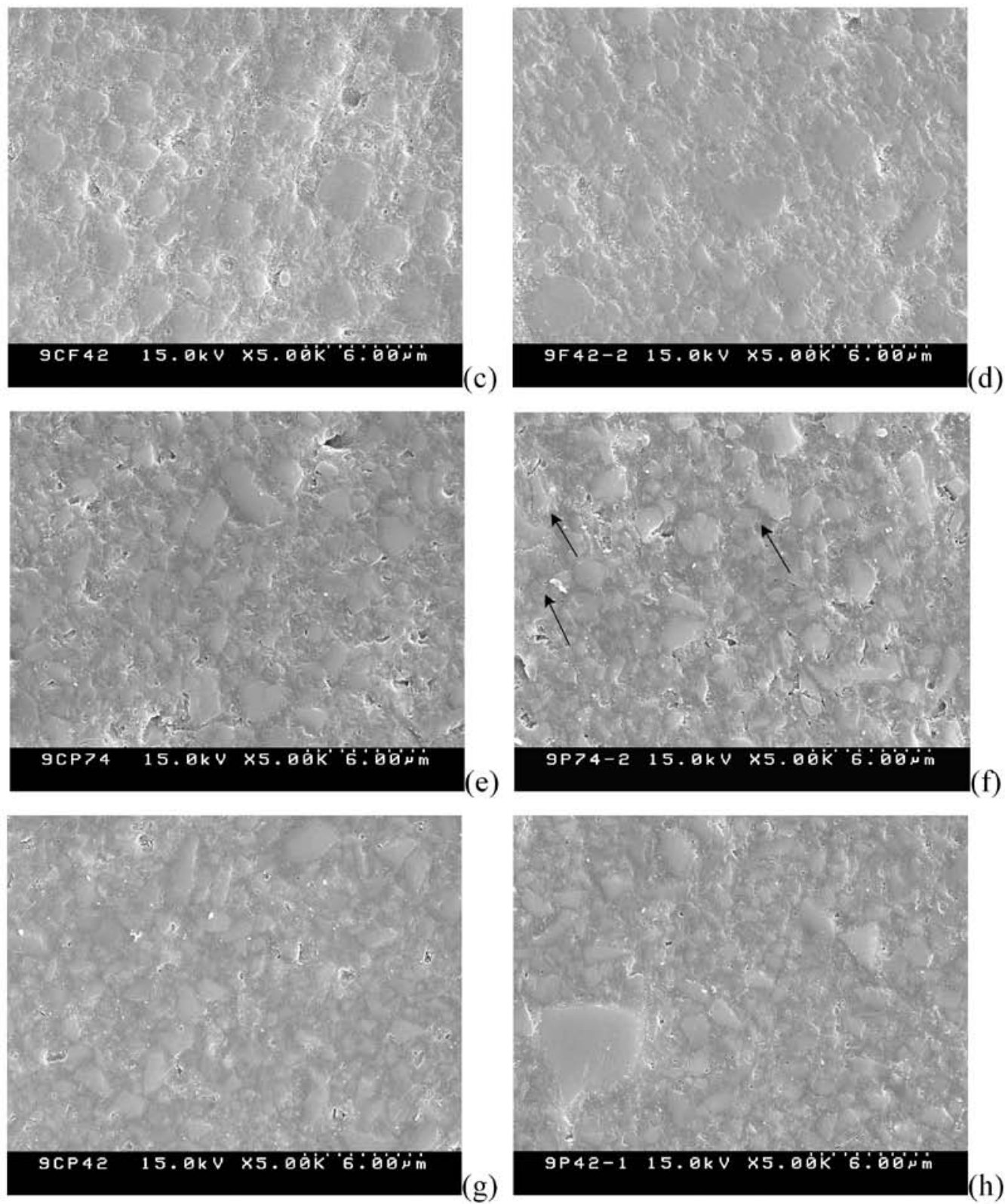

\section{(f)}

(e)

(g)

\section{(h)}

Fig. 3 Surface morphologies of specimens before (left column) and after (right column) the thermocycling process. a, b, e, f, i, j, m, and $\mathrm{n}: 700 \mathrm{~mW} / \mathrm{cm}^{2}$ and $40 \mathrm{~s}$; the rest at $400 \mathrm{~mW} / \mathrm{cm}^{2}$ and $20 \mathrm{~s}$. a $-\mathrm{d}$ : FP; $\mathrm{e}-\mathrm{h}: \mathrm{PD} ; \mathrm{i}-\mathrm{l}: \mathrm{TPH} ; \mathrm{m}-\mathrm{p}$ : $\mathrm{Z} 2$. 

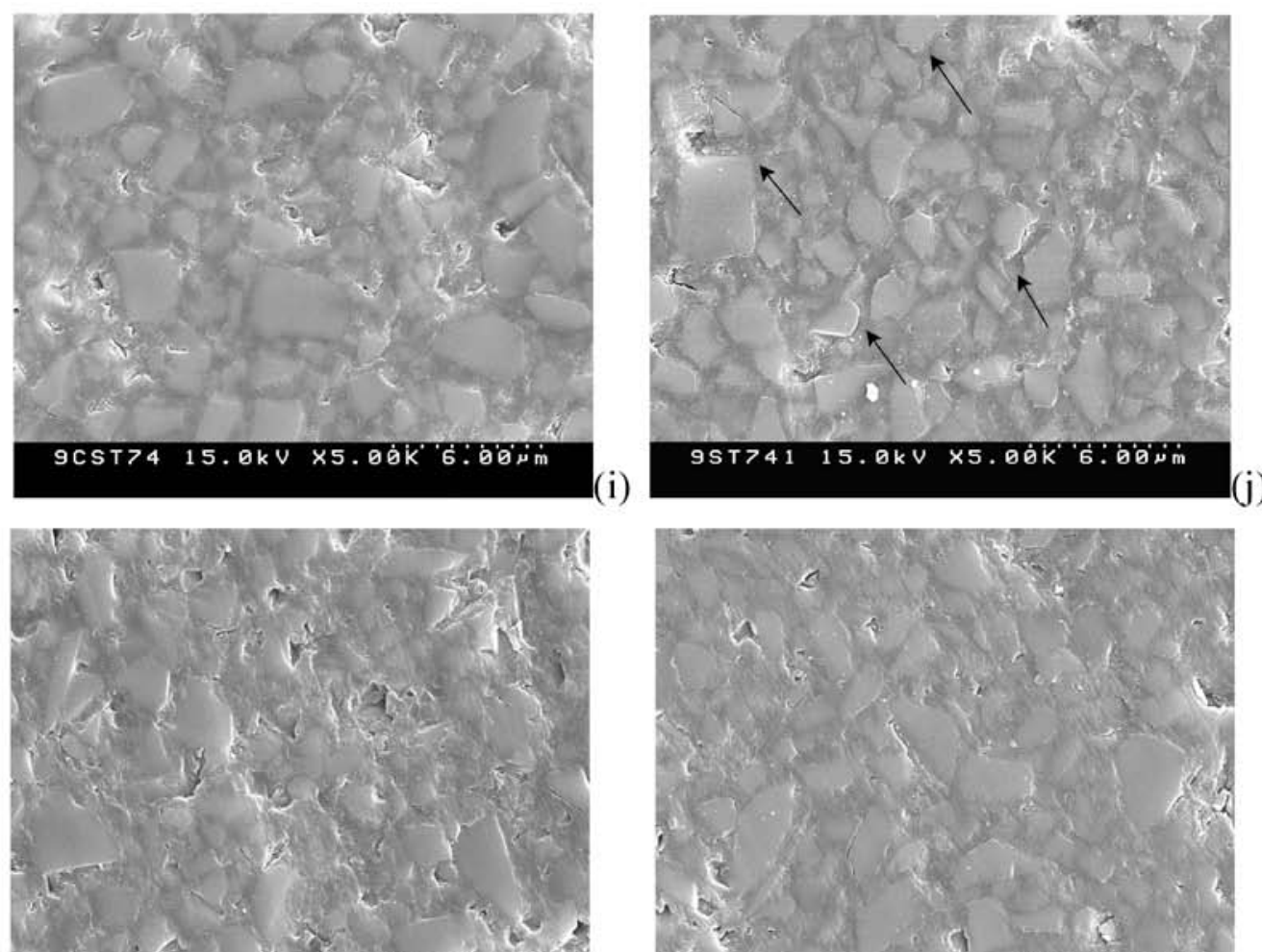

$9 \mathrm{CST} 4215.0 \mathrm{kV} \times 5.0 \mathrm{k}^{\prime} \mathrm{6}^{\circ} \mathrm{\theta}^{\circ} \mathrm{j}_{\mathrm{m}}$

(k)
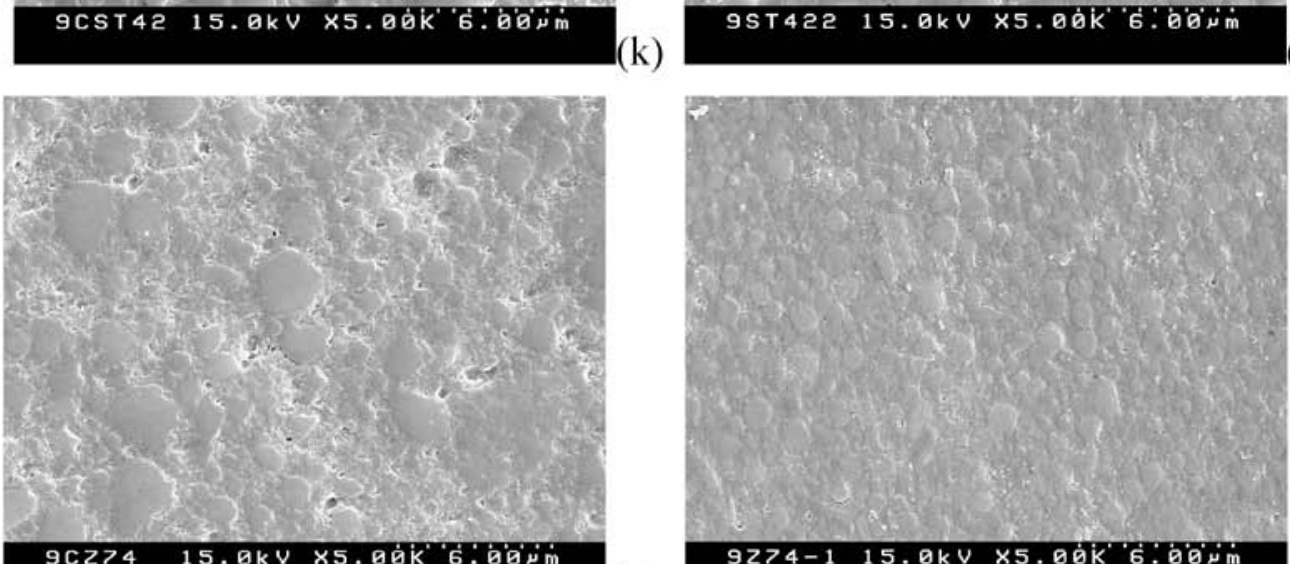

(1)

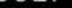

(m)

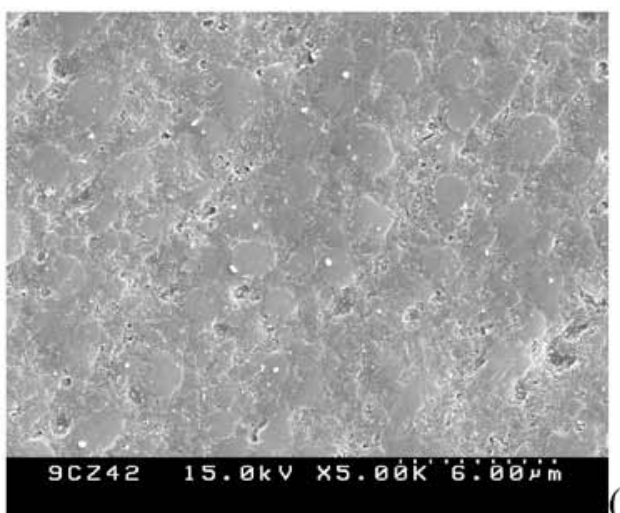

9274-1 15. $1 \mathrm{kV} \times 5.80 \mathrm{k}$ 6:

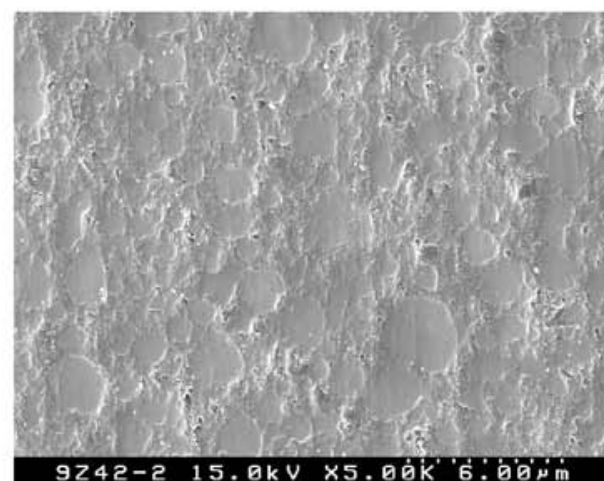

(o)

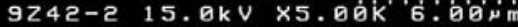

(n)

Fig. 3 Surface morphologies of specimens before (left column) and after (right column) the thermocycling process. a, b, e, f, i, j, m, and n: $700 \mathrm{~mW} / \mathrm{cm}^{2}$ and $40 \mathrm{~s}$; the rest at $400 \mathrm{~mW} / \mathrm{cm}^{2}$ and $20 \mathrm{~s} . \mathrm{a}-\mathrm{d}$ : FP; $\mathrm{e}-\mathrm{h}: \mathrm{PD} ; \mathrm{i}-\mathrm{l}: \mathrm{TPH} ; \mathrm{m}-\mathrm{p}$ : $\mathrm{Z} 2$. 
matrix (indicated with arrows). In particular, TPH exhibited more apparent detachment regardless of energy density.

\section{DISCUSSION}

In the photopolymerization of composite resins, light intensity is a critically important factor as it is directly related to the number of photons delivered. In the blue region, photons are absorbed by the photoinitiator $\mathrm{CQ}$, leading to the $\mathrm{n} \rightarrow \pi^{*}$ transition of the dicarbonyl group ${ }^{21}$. The number of photons emitted by a curing light source per second $\cdot \mathrm{cm}^{2}$ can be roughly calculated by dividing light intensity by photon energy ${ }^{22)}$. If light attenuation were not taken into consideration, the number of photons approximated for a typical blue light of $470 \mathrm{~nm}$ would be $1.7 \times 10^{18}$ photons $/ \mathrm{s} \cdot \mathrm{cm}^{2}$ and $9.5 \times 10^{17}$ photons $/ \mathrm{s} \cdot \mathrm{cm}^{2}$ for $700 \mathrm{~mW} / \mathrm{cm}^{2}$ and $400 \mathrm{~mW} / \mathrm{cm}^{2}$ respectively.

With regard to the photoinitiator, the number of CQ molecules can reach $2.4 \times 10^{18}$ molecules $/ \mathrm{cm}^{3}$ for a 0.2 wt\% concentration of $\mathrm{CQ}$, with $30 \%$ monomer in composite resin at a $1.1 \mathrm{~g} / \mathrm{cm}^{3}$ monomer density ${ }^{23)}$. In 1.5-mm-thick specimens, the number of $\mathrm{CQ}$ molecules was equivalent to $0.36 \times 10^{18}$ molecules/ $\mathrm{cm}^{2}$. For 10-second irradiation under $700 \mathrm{~mW} / \mathrm{cm}^{2}$ and 20-second irradiation under $400 \mathrm{~mW} / \mathrm{cm}^{2}$, the numbers of photons were $6.7 \times 10^{17}$ photons $/ \mathrm{cm}^{2}$ and $7.6 \times 10^{17}$ photons $/ \mathrm{cm}^{2}$ respectively. These numbers were in the same range as the number of $\mathrm{CQ}$ molecules, suggesting that the tested six light curing conditions did not pose any significant problem in polymerizing the chosen specimens. The similar range of microhardness values for each product with six different light-curing conditions was a testament to the sufficient number of photons required for activating the photoinitiators. However, a higher light intensity with a longer light-curing time yielded greater microhardness values than the rest of the cases.

The conversion of monomer molecules into a polymer network is accompanied by a condensing of the molecular chain. The shrinkage process continues until the reaction is terminated ${ }^{23,24)}$. Except there be significant local porosity or defects in the specimen, local shrinkage typically translates into an observable macroscopic shrinkage ${ }^{25}$. In many cases, polymerization shrinkage in a composite resin has been reported to cause clinically significant problems.

Measurement in our study showed that the shrinkage process began almost immediately after the onset of light irradiation. This immediate response seemed natural because the numbers of photons in the chosen light-curing conditions were sufficient to activate the photoinitiator and initiate the polymerization process within a second. According to the measurement results, polymerization shrinkage reached the maximum at about 40 seconds after the onset of light irradiation. After which, polymerization shrinkage did not increase but remained at a plateau although light irradiation continued uninterrupted.

In Table 3, the lower maximum polymerization shrinkage values under the same light intensity but with a shorter light-curing time than 40 seconds could explain this finding. If light-curing time were shorter than 40 seconds, the specimens did not have sufficient time to be shrunken. Conversely, if the light-curing time were much longer than 40 seconds, the specimens would have enough time to be shrunken. Since a light intensity of $400 \mathrm{~mW} / \mathrm{cm}^{2}$ delivered enough photons to activate the CQ molecules, it no longer mattered if light intensity were greater than $400 \mathrm{~mW} / \mathrm{cm}^{2}$. It seemed that the light-curing time played a more influential role in that the longer the light-curing time, the greater was the likelihood for maximum polymerization shrinkage to occur. However, it must be put into perspective that this statement is valid only for the shortduration evaluation (measurement for only a few minutes) in this study. Pertaining to longer lightcuring times (measurement for a few hours), further investigations are needed to assess if this statement is still valid.

In the present study, the estimated coefficients of thermal expansion ranged approximately between 40 and $59 \times 10^{-6} /{ }^{\circ} \mathrm{C}$. These values were much higher than those of enamel and dentin. (The reported coefficients of thermal expansion of enamel and dentin were approximately $17 \times 10^{-6} /{ }^{\circ} \mathrm{C}$ and $11 \times 10^{-6}$ $/ \times \mathrm{C}$ respectively ${ }^{26}$ ). In general, the coefficients for dental composites reportedly ranged between $20 \times 10^{-6} /{ }^{\circ} \mathrm{C}$ and $80 \times 10^{-6} /{ }^{\circ} \mathrm{C}^{27,28)}$. A lower coefficient of thermal expansion under a higher energy density could be ascribed to sufficient polymerization.

When compared to the polymerization shrinkage results, different features as presented by the coefficient of thermal expansion results could be due to 24-hour aging. Maximum polymerization shrinkage values serve to reflect the dynamic change during the light curing process. On the other hand, at 24 hours after light curing, specimens would be stabilized and additional shrinkage would be minimal. Indeed, the same trend as observed in the values of microhardness and coefficient of thermal expansion strongly supported the role of and contribution by aging. Based on Fig. 2, the correlation between the coefficient of thermal expansion and polymerization shrinkage can be derived from the acquired data. In each correlation curve, as the curve increased, the filler content of the specimens decreased although it was not shown is 
the given figure. In this figure, the slope of the linearly-fitted graph seemed to depend on energy density. As a result, the higher the energy density, the steeper was the slope of the graph. The reduction in coefficient of thermal expansion through the thermocycling process was probably related to the additional polymerization by aging.

The thermocycling process involves repeated cooling and heating processes. The heating process may then induce an additional post-curing process. Post-curing by heat is related to the formation of free radicals $^{29)}$. In general, the free radical half-life of light-cured composite resins is greatly reduced by aging, by an increase of temperature, and by the amount of filler particles present. However, the thermocycling process also involves a subsequent cooling process which may inactivate the produced free radicals and thereby extend the free radical halflife $^{30)}$. As a result of repeated cooling and heating, free radical half-life may not be much affected. However, since 10,000 cycles of 30-second cooling and heating takes approximately seven days, additional aging effect can take place during this extended period.

The range and gradient of a temperature change in the actual oral cavity is generally complicated. In most cases, the temperature in the mouth depends on the temperature of the food consumed and the dietary habits of the individual. Thermocycling was adopted in this study to mimic the oral environment. It must be mentioned that although repeated heating and cooling in $60^{\circ} \mathrm{C}$ and $4^{\circ} \mathrm{C}$ baths were performed, this process was not complicated enough to mimic the real oral environment. Moreover, the number of 10,000 thermocycles employed in this study was also arbitrary. Nonetheless, this number of thermocycles is frequently chosen for thermocycling tests ${ }^{31)}$.

Consecutive heating and cooling of a specimen will induce a temperature gradient in the specimen and may form a weak stress which is not sufficient to immediately fracture the specimen. Such heating and cooling can also affect the fillers and resin matrix in different manners, since fillers and resin matrix have different thermal expansion properties. Consequently, repeated expansion and contraction due to external thermal stimulus can detach fillers from the resin matrix. In the current study, the specimens tested had two different filler shapes: round and irregular-shaped with sharp edges. Since microdefects grow and propagate as a crack along a (relatively) straight line rather than in a circle, detachment of irregularly shaped fillers with sharp edges seemed natural. Detachment was not observed for the round fillers. Additionally, bigger fillers exhibited more apparent detachment than the smaller ones.

Within the limitations of the present study, it was concluded that light-curing dental composite resins at a higher energy density was beneficial to acquiring higher microhardness values and lower coefficients of thermal expansion. On the other hand, maximum polymerization shrinkage also reached a higher value at a higher energy density as compared to the case of lower energy density. However, the maximum polymerization shrinkage values obtained in the present study reflected only a short-term effect taking place during light curing. For a more concrete and holistic conclusion, it is necessary to measure polymerization shrinkage after an extended period of time.

\section{REFERENCES}

1) Hofmann N, Hugo B, Klaiber B. Effect of irradiation type (LED or QTH) on photoactivated composite shrinkage strain kinetics, temperature rise, and hardness. Eur J Oral Sci 2002; 110: 471-479.

2) Deb S, Sehmi H. A comparative study of the properties of dental resin composites polymerized with plasma and halogen light. Dent Mater 2003; 19: $517-522$.

3) Nomoto R, McCabe JF, Hirano S. Effect of aperture size on irradiance of LED curing units. Dent Mater 2004; 20: 687-692.

4) Soares LE, Martic AA, Pinheiro AL, Pacheco MT. Vicker's hardness and Raman spectroscopy evaluation of a dental composite cured by an argon laser a halogen lamp. J Biomed Opt 2004; 9: 601608.

5) Uhl A, Michaelis C, Mills RW, Jandt KD. The influence of storage and indenter load on the Knoop hardness of dental composites polymerized with LED and halogen technologies. Dent Mater 2004; 20: 2128.

6) Wiggins KM, Hartung M, Althoff O, Wastian C, Mitra SB. Curing performance of a new-generation light-emitting diode dental curing unit. J Am Dent Assoc 2004; 135: 1471-1479.

7) Ruyter IE, Oysaed H. Conversion in different depths of ultraviolet and visible light activated composite materials. Acta Odontol Scand 1982; 40: 179-192

8) Chae KH, Sun GJ. Phenylpropanedione: a new visible light photosensitizer for dental composite resin with higher efficiency than camphorquinone. Bull Korean Chem Soc 1998; 19: 152-154.

9) Loshaek S, Fox T. Cross-linked polymers. 1. Factors influencing the efficiency of cross-linking in copolymers of methyl methacrylate and glycol dimethacrylate. J Am Chem Soc 1953; 75: 35443550.

10) Patel MP, Braden M, Davy KW. Polymerization shrinkage of methacrylate esters. Biomaterials 1987; 8: 53-56.

11) Goldman M. Polymerization shrinkage of resin based restorative materials. Aust Dent J 1983; 28: 156-161.

12) Feilzer AJ, De Gee AJ, Davidson CL. Curing contraction of composites and glass-ionomer cements. J Prosthet Dent 1988; 59: 297-300. 
13) Kemp-Scholte CM, Davidson CL. Marginal sealing of curing contraction gaps in class $\mathrm{V}$ composite resin restorations. J Dent Res 1988; 67: 841-845.

14) Lai JH, Johnson AE. Measuring polymerization shrinkage of photo-activated restorative materials by a water-filled dilatometer. Dent Mater 1993; 16: $172-176$.

15) Davidson CL, Feilzer AJ. Polymerization shrinkage and polymerization shrinkage stress in polymerbased restoratives. J Dent 1997; 25: 435-440.

16) Rueggeberg FA, Caughman WF, Curtis JW. Effect of light intensity and exposure duration on cure of resin composite. Oper Dent 1994; 19: 26-32.

17) Oberholzer TG, Pameijer CH, Grobler SR, Rossouw RJ. The effect of different power densities and method of exposure on the marginal adaptation of four light-cured dental restorative materials. Biomaterials 2003; 24: 3593-2598.

18) Barros GK, Aguiar FH, Santos AJ, Lovadino JR. Effect of different intensity light curing modes on microleakage of two resin composite restorations. Oper Dent 2003; 28: 642-646.

19) Rahiotis C, Affodite CR, Loukidis M, Vougiouklakis G. Curing efficiency of various types of light-curing units. Eur J Oral Sci 2004; 112: 89-94.

20) Yap AU, Soh MS, Han TT, Siow KS. Influence of curing lights and modes on cross-link density of dental composites. Oper Dent 2004; 29: 410-415.

21) Tsai L, Charney E. The triplets states of alphadicarbonyls. J Phys Chem 1969; 73: 2462-2463.

22) Asmussen E, Peutzfeldt A. Mechanical properties of heat treated restorative resins for use in the inlay/ onlay technique. Scand J Dent Res 1990; 98: 564-
567.

23) Venhoven BA, de Gee AJ, Davidson CL. Light initiation of dental resins: dynamics of the polymerization. Biomaterials 1996; 17: 2313-2318.

24) Rees JR, Jacobsen PH. The polymerization of composite resins. Dent Mater 1989; 51: 41-44.

25) Silikas N, Al-Kheraif A, Watts DC. Influence of $\mathrm{P} / \mathrm{L}$ ratio and peroxide/amine concentrations on shrinkage-strain kinetics during setting of PMMA/ MMA biomaterial formulations. Biomaterials 2005; 26: 197-204.

26) Xu HC, Liu WY, Wang T. Measurement of thermal expansion coefficient of human teeth. Aust Dent J 1989; 34: 530-535.

27) Hashinger DT, Fairhurst CW. Thermal expansion and filler content of composite resins. J Prosthet Dent 1984; 52: 506-510.

28) Versluis A, Douglas WH, Sakaguchi RL. Thermal expansion coefficient of dental composites measured with strain gauges. Dent Mater 1996; 12: 290-294.

29) Wu W, Fanconi BM. Post-curing of dental restorative resin polymer. Polymer Eng \& Sci 1983; 23: 704-707.

30) Burtscher P. Stability of radicals in cured composite materials. Dent Mater 1993; 9: 218-221.

31) Gale MS, Darvell BW. Thermal cycling procedures for laboratory testing of dental restorations. J Dent 1999; 27: 89-99.

32) Braem M, Finger WJ, van Doren VE, Lambrechts P, Vanherle G. Mechanical properties and filler fraction of dental composites. Dent Mater 1989; 5: 346-349. 